\title{
Zwei Hermaphroditen von Lasiocampa pini L.
}

\section{Beschrieben von Fritz A. Wachtl in Wien.}

Einer dieser beiden Zwitter wurde vor Jahren von mir aus Raupen erzogen, die ich in Galizien auf Weymouthskiefern (Pinus Strobus L.) gesammelt hatte.

Dieses Exemplar ist ein sogenannter halbirter Zwitter, indem die rechtsseitige Hälfte vollkommen männlich und bedeutend kleiner als die grössere, linksseitige, weibliche Hälfte ist.

An der männlichen Hälfte besitzt der Vorderflügel einen dunkelbraunen Grundton, das Wurzelfeld und die Querbinde, welche nur auf der Aussenseite gezackt ist, sind intensiv rothbraun gefärbt, ohne dunklere Einsäumung, der weisse Mittelfleck ist klein, verloschen, aber noch kenntlich; der Hinterfl ü gel ist röthlich-graubraun, das Spitzendrittel dunkler braun gefärbt.

An der weiblichen Hälfte zeigt der Vorderflügel einen aschgrauen, durch eingestreute rothbraune Schuppen etwas melirten Grundton, das Wurzelfeld und die Querbinde, letztere beiderseits gezackt und, namentlich auf der Aussenseite, auch mit dunkleren Linien und Flecken eingesäumt, sind intensiv rothbraun, der Mittelfleck ist sehr deutlich, grösser und rein weiss gefärbt; der H in terflügel ist einfärbig, röthlichgraubraun. Fühler, Augen, Beine und Beschuppung des Körpers sind auf der rechtsseitigen Hälfte vollkommen männlich, auf der linksseitigen weiblich, der Körper ist auf der ersteren dunkler, auf der letzteren lichter rothbraun gefärbt. Ueber die Genitalien lässt sich ohne nähere Untersuchung, welche ein Entfernen der Schuppen und Haare bedingen würde, Bestimmtes nicht sagen.

Einen, diesem in der Färbung sehr ähnlichen Zwitter hat J. Lederer in der Wiener Entom. Monatschr. 1863, T. VII, pag. 28 beschrieben und in Fig. 14 auf Taf. I abgebildet.

Ein zweiter Hermaphrodit, welchen die beigegebene Figur zeigt, wurde von mir im Jahre 1881 aus Puppen erzogen, die ich der Güte des Herrn Forstverwalters Minnichsdorfer verdankte. Sie stammten aus einer circa 1.7 ha grossen, in der Nähe von Wr.-Neustadt gelegenen, mit Schwarzföhren bestockten Waldparzelle, auf der im Jahre 1882 sämmtliche Bäume durch die Raupen dieses Spinners vollständig kahl 
gefressen wurden. Um einer Weiterverbreitung des Uebels zu steuern, wurde dieses Wäldchen, zufolge behördlicher Anordnung und mit Anwendung der nöthigen Vorsichtsmassregeln, am 4. Juli niedergebrannt.

Auch dieses Exemplar ist ein halbirter Zwitter, dessen rechtsseitige Hälfte männlich, die linksseitige weiblich ist; die Differenz, sowohl in den Grössenverhältnissen, als auch in der Färbung der beiden Hälften, ist jedoch bei diesem Stücke eine weit weniger auffällige, als bei dem vorhin beschriebenen Exemplare.

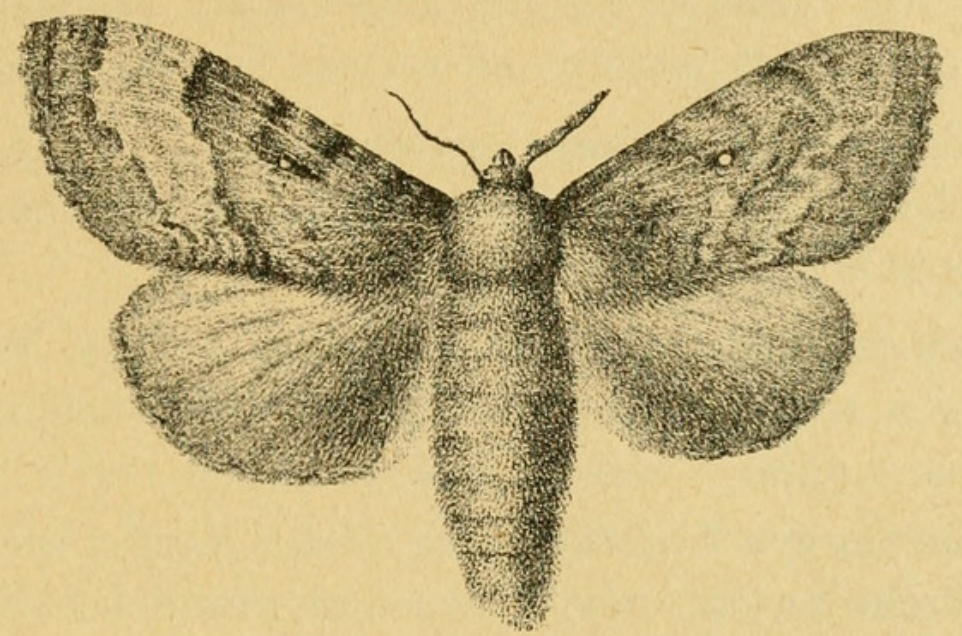

Beide Vorderflügel haben einen dunkel graubraunen Grundton, welcher durch viele eingestreute weisse Schuppen melirt erscheint. Die Wurzelfelder sind nicht, die Querbinden nur wenig lichter als der Grundton gefärbt uud letztere namentlich auf der rechtsseitigen, männlichen Hälfte, beiderseits von wenig ausgeprägten, verloschenen, undeutlich dunkleren Zackenlinien eingesäumt; die Mittelflecke sind deutlich, rein weiss, jener der männlichen Hälfte grösser als der andere. Ausserdem stehen noch auf beiden Flügeln am Vorderrande einige verloschene, in die Flïgelfläche schief gegen den Innenwinkel ziehende, dunklere Flecken. Beide Hinterflügel sind einfarbig, bräunlichgrau, gegen den Saum zu und längs des Innenrandes dunkler verwaschen.

Der Thorax ist einfarbig, graubraun; der Hinterleib gelblichgrau, auf der männlichen Hälfte jedoch etwas dunkler als auf der anderen. Fühler, Augen, Beine und Beschuppung des Körpers sind bei diesem, sowie bei dem anderen Exemplare, rechtsseitig vollkommen männlich, linksseitig weiblich. Ueber die Genitalien lässt sich auch bei diesem Stücke ohne genauere Untersuchung nichts Näheres sagen. 


\section{$2 \mathrm{BHL}$ Biodiversity Heritage Library}

Wachtl, Fritz A. 1884. "Zwei Hermaphroditen von Lasiocampa pini L." Wiener entomologische Zeitung 3, 72-73. https://doi.org/10.5962/bhl.part.13822.

View This Item Online: https://www.biodiversitylibrary.org/item/43792

DOI: https://doi.org/10.5962/bhl.part.13822

Permalink: https://www.biodiversitylibrary.org/partpdf/13822

\section{Holding Institution}

Smithsonian Libraries

\section{Sponsored by}

Smithsonian

\section{Copyright \& Reuse}

Copyright Status: NOT_IN_COPYRIGHT

This document was created from content at the Biodiversity Heritage Library, the world's largest open access digital library for biodiversity literature and archives. Visit BHL at https://www.biodiversitylibrary.org. 